\title{
La antropología (audio)visual frente a las Nuevas Tecnologías de la Información y la Comunicación. Apuntes en torno a una reflexión
}

Jorge Grau Rebollo

Universidad Autónoma de Barcelona

\begin{abstract}
Hablar de nuevas tecnologías y de la influencia que pueden llegar a tener, o se les atribuye, en las sociedades humanas entre las cuales se esparcen, abre un amplio campo de discusión, pero también puede inducir a algunas confusiones. Ciertamente, todos podemos tener conciencia de hasta qué punto estamos aprendiendo a vivir con tecnologías que hace apenas medio siglo eran prácticamente desconocidas. Cada vez nos movemos con mayor familiaridad en conversaciones o debates que convierten estas Nuevas Tecnologías de Información y Comunicación (NTIC) en la clave del "desarrollo" de las sociedades industriales tecnológicamente más complejas. No obstante, esos mismos discursos mezclan ámbitos y niveles distintos. En unas ocasiones el reduccionismo excesivo (por ejemplo, la asociación casi exclusiva de las NTIC con la extensión masiva de redes de comunicación que actúan a través de ordenador - Internet, Usenet, etc.-) o, en otras, la confusión terminólogica (hablar de tecnología cuando en realidad se está haciendo referencia a técnicas, o considerar científico aquello que no excede un dominio estrictamente tecnológico) inducen a explorar dimensiones unilineales del fenómeno de las NTIC. Este artículo es un intento de situar algunos elementos dentro de este amplio debate, así como invitar a la reflexión sobre algunas de esas dimensiones. Al menos, de aquellas que más directamente inciden en las ciencias sociales y desde las cuales los investigadores tratamos de aproximarnos a ese entorno, cada vez más difuso, que llamamos "realidad".

Se partirá para este fin del bagaje que aportan las distintas líneas teóricas que conforman la antropología visual y, por extensión, la antropología social y cultural. La intención no es, no puede ser, tratar con propósito exhaustivo el "impacto" de las nuevas tecnologías de la información y la comunicación en nuestro sistema social, sino más bien reflexionar acerca de cómo pueden ayudarnos los armazones teóricos que la antropología audiovisual nos aporta a entender las nuevas perspectivas que dichas tecnologías abren a los científicos sociales. La relativa novedad del fenóme-
\end{abstract}


no obliga a moverse con cautela frente a posiciones en exceso doctrinales o meramente especulativas, pero al mismo tiempo se cuenta con la ventaja de trabajar desde las propias entrañas del cambio. Se entienden aquí las NTIC como una nueva ola de cambio tecnológico, técnico e instrumental, pero también - y de forma significativa - como una nueva forma de entender al anthropos social ante las estrategias de vida que él mismo genera. Este discurso constituye un modesto intento de meditar acerca de todas estas cuestiones con el ropaje teórico de un antropólogo que ha encontrado en el audiovisual como método, herramienta y objetivo terminal en sí mismo un fecundo y estimulante campo de investigación de aquello que llamamos "sociedad" y "cultura".

\section{A propósito de la teCnOlogía. Matices en torno a unA CONFusión}

Nicholas Negroponte (citado en Colombain 1997) opinaba que "L'informatique n'est pas plus une histoire d'ordinateur, c'est un mode de vie.. Puede deducirse entonces que ciertas aproximaciones teóricas provenientes mayoritariamente de las disciplinas sociales (comunicación audiovisual, sociología, más recientemente antropología) que toman las NTIC como base referencial, han dejado de considerar la máquina como el nudo problématico. En su lugar, la relación o interrelación entre los usuarios y las múltiples prestaciones a las que se tiene acceso a través de estos ingenios se convierte en el nuevo objeto de análisis. Ya no cabe pensar en el dominio del ordenador como un conocimiento propio de una élite cuyo acceso parecía cada vez más restringido. Al contrario. El conocimiento que se precisa para manejar ese ordenador (como usuario) es cada día compartido por más gente a lo largo y ancho del planeta. No debe confundirse este conocimiento tan generalizado, con el saber que supone la especialidad de programadores y técnicos, que les permite configurar complejos programas y el software sin el cual ninguno de los usuarios nos atreveríamos a adentrarnos en aquello que se ha dado en llamar "la era de la informática”.

Esta primera diferenciación entre especialista y usuario remite directamente a una segunda dicotomía, en realidad una dicotomía múltiple, que delimita - y por tanto diferencia - la ciencia de la tecnología; la tecnología de la técnica y aún ésta de los instrumentos ${ }^{1}$.

1 Juan Cueto (Rispa 1985) considera que nuestra sociedad está cada vez más influenciada por el discurso tecnológico y científico, que operan a su vez sobre una dualidad esencial: la construcción del saber sobre la base de la complejidad y, por tanto, opuesto a la simplificación. De esta manera "Esta nuevas tecnologías modifican 
Daniel Chandler (1998) repara en este extremo, al tiempo que introduce una nueva variable esencial a la hora de analizarlo: la historia. Debe entenderse aquí "historia" en el sentido de transformación en la definición y uso de los conceptos, así como su integración o derivación de cuerpos teóricos globales. Esta transformación puede llevarse a cabo a lo largo de siglos o en el breve espacio de una década. Por ejemplo, la noción misma de "conocimiento científico" es una construcción cultural, además de histórica. Es cultural porque surgió en el contexto del sistema de valores y creencias de un determinado grupo humano. $\mathrm{Y}$ es histórica porque se gestó en un momento concreto de la existencia de ese grupo. De esta suerte, instalados en la perspectiva temporal que nos otorga sabernos insertados en la historia "nosotros" que, en un resbaladizo ejemplo de generalización conceptual, nos denominamos "sociedad occidental" u "OCcidenten), podemos examinar grupos humanos distintos en segmentos temporales igualmente diversos. Si este examen responde a las expectativas teóricas generadas por la autodenominada "Ciencia" — proyectada etnocéntricamente como patrón de saber-, el conocimiento que pueda derivarse se supondrá científico.

Chandler advierte de la fugacidad con que los conceptos conservan su significado. En el siglo XVII, tecnología ${ }^{2}$ se aplicaba principalmente al estudio sistemático de las artes, o bien al de un arte en particular. Un siglo más tarde, el término pasó a aplicarse a las artes mecánicas. A mediados del siglo xIX, tecnología se refería a las artes prácticas. En el tránsito hacia el siglo $\mathrm{xx}$, se operó la distinción entre ciencia y tecnología que aun subyace en buena parte de los debates en la actualidad: la primera se asoció a conocimiento mientras que la última se refería principalmente a una aplicación práctica dentro de un ámbito concreto de ese conocimiento. Curiosamente, parece que el término técnica no quedó registrado hasta 1817 , refiriéndose a la ejecución artística —en particular referida a la música o la pintura. Sin embargo, en el siglo $\mathrm{xx}$, Chandler

nuestra manera de representar los fenómenos de la cultura y la naturaleza" (p. 2) interviniendo en los propios procesos de conocimiento. El límite de este conocimiento, según Manuel Martín Serrano (Rispa 1985), “(...) está establecido por la biología del hombre y no por la tecnología" (p. 208). José Luis López de Aranguren, en la ponencia de clausura (idem) advierte que la sociedad occidental entiende la cultura como esencialmente tecnocientífica.

2 Y aun antes, como recuerda Aranguren (Rispa 1985), cabría hablar de tecnología. Por ejemplo en la confección del primer libro. Y continuando con un ejercicio de retroyecciones históricas, podríamos referirnos a la tecnología que permitió desarrollar la óptica, los engranajes, el gobierno de embarcaciones por medio de un timón, etc. 
(1998: 1) detecta un cambio significativo en la "convención lingüística". Tanto de forma denotativa como connotativa, el término tecnología se ha empleado cada vez con mayor profusión por parte de la comunidad académica, los especialistas y el público en general. Pero esta multiplicidad de uso ha discurrido paralela a la diversificación de contenidos que se le asocian. Por ejemplo, actualmente incluso hay quien aplica este término para referirse al conocimiento y dominio de estados psicológicos. La convención, no obstante, parece ser la de entender por tecnología la aplicación práctica de ciertos conocimientos científicos. Acotada así, la ciencia quedaría confinada a la designación del saber teórico sistemático basado en la observación, la experiencia acumulada, la experimentación, el análisis, la elaboración de hipótesis contrastables, la práctica deductiva y la facultad predictiva.

No es infrecuente caer en otra ambigüedad: la que confunde los términos máquina y técnica. Las máquinas no son sino elementos empíricos, tangibles. La técnica, por el contrario, hace referencia al amplio elenco de procedimientos de que hace uso la tecnología (o hasta cierto punto también la ciencia) para concretarse. La sinécdoque en virtud de la cual denominamos el contenido por el continente o el todo por la parte entraña el riesgo de familiarizar tanto este uso que acabe por confundirse. En un nivel muy elemental, prácticamente cualquier miembro de nuestra sociedad es capaz de manejarse con las funciones básicas de un aparato telefónico (clescolgar cuando suena, hablar y colgar al finalizar la conversación), sin que por ello deba necesariamente dominar el saber tecnológico que hay detrás. Muchos somos los que trabajamos a diario con la ayuda de un ordenador (máquina), sin que por ello seamos capaces de entender cómo funciona. En otras palabras, de un modo general entre la población, las NTIC (o, con mayor propiedad, las máquinas e instrumentos que generan las NTIC) se consumen, pero no por ello ese mismo sector amplio de la sociedad entiende el saber tecnológico que les precede. Los instrumentos se incorporan a la rutina de aquello que llamamos vida social, por más que el control de los saberes que permiten crearlos sigue siendo el reducto de un sector mucho más limitado de la población.

En consecuencia, no debe confundirse la difusión en una sociedad (en algunos casos espectacular en los últimos años) de artefactos fruto de saberes tecnológicos determinados que han permitido su construcción, con el incremento del "nivel científico" en esa sociedad. Debe evitarse caer en el aforismo falaz que induce a medir este "nivel científico" en función del número de aparatos que se consumen. De hacerlo, sería como asimilar el nivel de inteligencia a la capacidad de almacenar datos. En ese caso los entes más inteligentes de nuestra sociedad serían las enciclopedias, los 
ordenadores con una descomunal capacidad de memoria ROM (Read Only Memory) o la Biblioteca Nacional.

Curiosamente, como han advertido numerosos teóricos, entre ellos Daniel Chandler (1998), la incorporación de nuevas tecnologías de la información y la comunicación al quehacer cotidiano de la sociedad urbana industrializada occidental (la que por defecto se convierte en modelo de generación y uso de las mismas) se lleva a cabo sobre un supuesto inicial que podría considerarse no problemático: las nuevas tecnologías (de manera análoga a la tecnología en general y como concreción evolucionada de ésta) se generan, perfeccionan y difunden por el bien general de la humanidad. Así, el progreso de un país se mide en buena parte por el nivel tecnológico que demuestra haber alcanzado, y uno de los indicadores en que se concreta este concepto es, sin duda, el grado de difusión y manipulación de aparatos, consecuencia directa de la fecundidad de dichos saberes tecnológicos. Sin embargo, y en contra de lo que pudiera parecer a primera vista, la percepción social que se tiene de estas concreciones tecnológicas está lejos de ser unidireccional.

\section{DiverSAS ACTITUDES ANTE LAS NTIC}

En junio de 1997, Beatriz Santana publica on line un artículo en el cual se recogen, a través de estudios orientados a examinar la relación que se establece entre saber tecnológico y sociedad, dos posturas notablemente polarizadas respecto a la acogida social de nuevos instrumentos. Un polo de este debate lo coparía la tecnofobia, entendiendo como tal el aprovechamiento perverso del saber (tecnológico) que conduce a los individuos a una deshumanización progresiva. La postura contraria -tecnofilia - la sostendrían aquellos que ven en la tecnología un saber acumulativo, progresivo y orientado al desarrollo y perfeccionamiento de la sociedad, a través de las múltiples actividades en que ésta se estructura. No obstante, la repulsión teórica extrema ofrece a la vez una doble vertiente: por un lado, la discusión acerca de la interrelación entre tecnología y sociedad, bien sea en términos deterministas en cualquiera de las dos direcciones, o en un plano más bien interactivo, y por otro, el uso que hacemos del saber tecnológico, y por extensión de las técnicas y los instrumentos que se le asocian.

Recogiendo ambas, Michael Shallis (Chandler 1998) constata la indisociable relación entre tecnología y sociedad en lo que a transformación mutua se refiere. En este sentido, la tecnología respondería, en principio, a necesidades cambiantes o acumulativas de la sociedad humana y, 
de la misma manera que el saber se construye a partir de la insatisfacción que causan los conocimientos precedentes, la tecnología sería un intento de superar las carencias y limitaciones de los productos y los saberes anteriores. El caso de la informática puede ser un ejemplo ilustrativo. El ser humano crea tecnología y, además, es su principal destinatario. La interacción entre persona y tecnología, dice Shallis, siempre ha transformado y siempre transformará el mundo, físico y social, que le rodea. Pero en este mismo proceso también el propio individuo experimenta una conversión, un cambio, en cierta medida una metamorfosis. Se ha hablado del Homo Videns para (entre otras cosas) denominar al ser humano ante las tecnologías audiovisuales. Aprendemos, también, a través de la imagen y el sonido. Baste en este sentido remitir a los múltiples ensayos publicados en referencia a la comunicación audiovisual, la pedagogía de la información audiovisual, etc. Se ha oído hablar a menudo del Homo Faber, el hombre - genérico- como hacedor, como constructor y no únicamente como usuario. Pudiera hacerse una pequeña broma al respecto y hablar del Homo Mutantis, transformado en su comportamiento social y transformador a su vez de la esfera cultural en que habita, mediante la incorporación, uso y actualización continua de aquello que se da en llamar tecnología.

Este ser humano, transformado de alguna manera por los propios saberes e instrumentos que genera, se encuentra (como Narciso ante las aguas del estanque) permanentemente fascinado por la tecnología. En especial, cuando entendemos esta tecnología como una dimensión más del propio ser del creador (McLuhan 1964). Esta fascinación parece irse traduciendo paulatinamente en dependencia. De esta manera, no sólo se convierte la tecnología en una muleta para el sostenimiento de las necesidades (postura tecnofilica) o en un lastre que debemos arrastrar en nuestra lucha permanente contra la deshumanización que provoca (orientación tecnofóbica), sino que incluso se llega al extremo de intentar solucionar los problemas, insatisfacciones o limitaciones que causa, con nueva tecnología. Así, superamos la tecnología con más tecnología. Y los actores sociales dependemos de ella cada vez en mayor medida para sobrevivir. Incluso en los ámbitos que parecen más nímios: transporte, comunicación, vestimenta, elaboración y manipulación de alimentos, etc.

Cuando esta dependencia deviene patológica —es decir, cuando el hombre no se cree capaz de vivir sin la tecnología- puede hablarse de teknosis (Biram 1978, citado en Chandler 1998). Biram entiende por teknosis la obsesión desmesurada por la tecnología que acaba confundiendo medios y fines, convirtiéndola en el fin en lugar de ser un medio para alcanzar metas más trascendentes. Biram habla de una auténtica enferme- 
dad del pensamiento. Narciso acaba creyendo que la imagen es su propio ser y en su deseo de poseerlo, de abrazarlo, se ahoga lentamente. Entre otras cosas porque se acaba instalando en la imagen que contempla y la configura al instante como su nueva realidad. Vive en ella y para ella. Necesita imperiosamente resultados inmediatos, vivir rodeado de instrumentos que le recuerden el nivel de progreso alcanzado y conviertan la dependencia en un espejismo.

Más allá de adhesiones incondicionales o predicciones apocalípticas, sí parece haber un cierto consenso sobre la neutralidad per se de que goza la tecnología, especialmente cuando nos estamos refiriendo a los artefactos que genera. La televisión, el ordenador, Internet, un teléfono móvil, etc., no son por sí mismos positivos o negativos. En todo caso la bondad o la perversión de estos instrumentos está en el uso que se haga de ellos. La técnica, la tecnología, los instrumentos, desde esta perspectiva y como recuerda Ellul (Chandler 1998), gozan de autonomía respecto a la dimensión moral. Planificar determinados programas en ciertas franjas horarias carece de efecto alguno sobre la audiencia a menos que se vean. El maquinismo cobró toda su fuerza cuando los operarios comenzaron a ser sustituidos por máquinas. La tecnología pervierte a las personas en el momento en que deja de ser ayuda para convertirse en necesidad, cuando deja de fabricar herramientas para encarnarse en objetivos ${ }^{3}$. No necesitamos quedarnos en los ensayos académicos para entender la relación estrecha entre ética y consumo, la literatura y el cine nos proveen de abundantes y notables ejemplos.

\section{VisuALIZACIÓN, CULTURA Y CiberesPaCio}

Samuel Ebersole (1995) recuerda que el fenómeno de masas en que se ha convertido el consumo de informática, a través de la adquisición de ordenadores domésticos y la creación de redes globales de comunicación como Internet, tuvo uno de sus puntos de partida en 1983. En ese año la revista Time decidió otorgar el premio de "Máquina del año" al denominado Personal Computer (ordenador o computador personal), que abreviadamente llamaban PC. Colombain (1997) nos aporta otro dato significativo: en 1995, apenas 13 años después, la venta de ordenadores supe-

3 Luis Racionero comenta, refiriéndose al impacto negativo de las NTIC en la vida laboral de los individuos: "Hace treinta años [1955, aproximadamente] el inventor de la cibernética advirtió que ésta provocaría tal paro que la crisis de los treinta quedaría pequeña" ("La informatización como paradigma cultural,, en Rispa 1985: 123). 
ró por vez primera la venta de automóviles. En este caso, unas cuantas cifras pueden ilustrar la magnitud y velocidad del cambio tecnológico e instrumental: en 1946, el primer ordenador que se fabricó pesaba 50 toneladas y podía realizar unas 5000 operaciones por segundo. Actualmente, pueden encontrarse ordenadores que contienen cerca de 9000 microprocesadores, capaces de realizar cerca de un billón de operaciones por segundo. A medida que pasan los años, los ordenadores multiplican su capacidad y sus prestaciones con un coste que no se dispara en la misma proporción. Así se entiende la percepción popular de que los ordenadores "bajan de precio" cada cierto tiempo. Actualmente, un CD-ROM (Compact Disc - Read Only Memory) puede llegar a contener información equivalente a más de 275.000 páginas de texto. Un DVD (Digital Versatile Disc) puede llegar a contener el equivalente a 7 o 26 CD-ROM, según el modelo. En los años 70, el Departamento de Defensa de los Estados Unidos proyectó un sistema de intercambio de información a través de un sistema de ordenadores entrelazados por medio de una red común (Internet ${ }^{4}$ ). En 1996, Colombain cifraba en unos 50 millones los internautas en todo el mundo. El incremento mensual estimado va desde el 10\% (Jones 1995) al $15 \%$ (Rheingold 1996). La previsión de crecimiento es espectacular: de quinientos millones a mil millones en el año 2000.

Estas magnitudes mueven a dos reflexiones diferentes. En primer lugar, se percibe la dimensión del fenómeno. En segundo lugar (combinando fechas y magnitudes) la velocidad de cambio. En efecto, el teléfono se inventó en 1870 (Resee et al. 1982), pero no se convirtió en artículo de consumo hasta comienzos del siglo XX. Sin embargo, en tan sólo 78 años multiplicó por 800 el número de aparatos en todo el orbe. La televisión vivió un ostracismo inicial de casi veinte años. Treinta y siete años después de empezar a difundirse, se habían vendido más de 70 millones de receptores únicamente en los EE.UU. Bernal (1985: 138) llega a afirmar: “La era de la Información constituye sólo una parte ínfima del período de existencia del hombre sobre la tierra. Sin embargo, la aceleración del desarrollo de la sociedad de la información es muy superior al de otras épocas, e incluso al ritmo de crecimiento de la población".

¿Qué nos sugiere esta velocidad de cambio? Indudablemente una calurosa acogida, de otra manera sería impensable alcanzar semejante ex-

4 No confundir con World Wide Web (WWW), cuya creación Trejo (1997) sitúa en el Laboratorio Europeo para la Física de Partículas, en Ginebra (Suiza) en 1989. Apareció a la luz pública en 1991 y poco más de dos años después su uso había crecido en un $41.000 \%$. El uso de la triple $W$ en todo el mundo creció en 1994 un $350.000 \%$ (p. 62). Más que el conocimiento, Trejo afirma que lo que "crece y se desarrolla" es el mercado que gira en torno a este nuevo sistema de comunicación. 
tensión. Pero esta aceptación vino asociada a determinadas variables que pueden permitir explicar las causas y las consecuencias del cambio. En primer lugar estaría la percepción de la tecnología y, especialmente, de sus concreciones instrumentales, como una evolución necesaria para el bienestar de la humanidad ${ }^{5}$. En segundo lugar, los beneficios que genera el consumo masivo de estos productos; beneficios que pueden entenderse como principalmente económicos, pero que tienen también una dimensión sutilmente distinta: el control de la información ${ }^{6}$. La competencia abierta por la conquista de un mercado en clara expansión reporta notables beneficios económicos (¿cómo si no entender parte de la dura batalla legal entablada entre la compañía Microsoft, presidida por el magnate de las nuevas tecnologías informáticas Bill Gates, y el gobierno federal de los EE.UU.?), pero también puede suponer el control de las llamadas autopistas de la información (Information Highways) con tendencia a situarse a la cabeza de la circulación de información en las sociedades con mayor penetración de las nuevas tecnologías electrónicas e informáticas.

Epistemología y economía de mercado se unen en esta arena de manera curiosa. Resee, Kubicek, Lange [et. al.] (1982: 52) proclaman: «Nuestro punto de partida epistemológico puede quedar descrito de la siguiente forma: las tecnologías de información son instrumentos, cuya aplicación se rige por y está al servicio de los intereses dominantes en la sociedad. Al mismo tiempo reclaman actuaciones estatales que permitan regular y garantizar la privacidad y confidencialidad en el uso de las NTIC. Además, Colombain aporta las siguientes cifras: en 1996, en los EE.UU. existían 8.200 .000 ordenadores conectados a Internet, en Alemania 550.000, en Francia 190.000... con todos los beneficios económicos que ello genera a los proveedores de la infraestructura técnica necesaria.

¿Qué niveles de discusión aparecen encriptados bajo estas consideraciones generales? Parece razonable suponer que la difusión de las NTIC en cualquier sociedad con infraestructura y capacidad técnica y económica suficiente para soportarlas, conlleva una reconsideración inmediata de diversas variables. Por ejemplo, la noción misma de progreso adquiere una

\footnotetext{
5 Por más que ya hemos revisado someramente posturas tecnofóbicas, las cuales en esencia niegan el contenido positivo de esta supuesta "evolución".

6 Ésta ha sido sin duda una de las puntas de lanza esgrimidas por los detractores del abuso tecnológico. Desde los códigos de barras adheridos a los productos de consumo diario, hasta el registro de conexiones que un usuario realiza en Internet, los individuos pasan a estar controlados por entes desconocidos, parapetados detrás de los artificios tecnológicos, que acaban por poseer información substancial sobre ellos: qué comen, qué música compran, qué tipo de libros leen, a qué grupos de discusión electrónica (foros virtuales) se subscriben, etc.
} 
nueva dimensión. Como ya se ha mencionado anteriormente, la percepción de la tecnología como un medio hacia la consecución del bienestar humano, pese a quedar en entredicho para ciertos sectores sociales, viene estrechamente ligada a la noción misma de evolucionismo. La sociedad progresa en tanto mejora, y mejora en tanto evoluciona. El barómetro de las NTIC, en lo que se refiere a la producción y también a la difusión y el consumo de las mismas - aunque sea a niveles distintosproporciona criterios presuntamente objetivos sobre el grado de desarrollo de un grupo humano. Sin embargo, no debemos perder de vista que consumir tecnología no implica adquirir conocimientos científicos o siquiera tecnológicos. A menudo, lo que se adquiere es el dominio relativo de un conjunto de procedimientos que permiten acceder a las prestaciones de artefactos concretos a partir de su operación. La compra de aparatos, como recuerda José Vicente Cebrián (en 1985) no significa imbuirse de saber, de logos. Comprar un ordenador y manejar un procesador de textos no significa que también adquiramos automáticamente el saber necesario para escribir novelas?

Esta falacia instrumental (asimilar la compra de productos tecnológicos al ingreso de conocimiento) tiene múltiples implicaciones. De entrada, la reflexión acerca de la manipulación informativa que se lleva a cabo. Comienza a hablarse a mediados de los ochenta de tecnocultura (Rispa 1985). En la transmisión de conocimientos culturales, el formato elegido para vehicular esta transmisión se concreta cada vez en mayor medida en soportes informáticos. Es aquí donde puede intentar resolverse una aparente paradoja: toda esta acumulación de producción tecnológica sí supone un saber concreto, la aprehensión de una tekbne y su transformación a partir de las necesidades cambiantes con las que se encuentran los especialistas. El logos científico se traduce en tekbne para su operatividad en dominios concretos. Esta traducción exige la formación de especialistas, un grupo de hombres y mujeres que efectivamente saben cómo. Pero la cuestión está en que este grupo es porcentualmente minoritario en cualquier sociedad. Pudiera decirse, sin propósito dogmático, que el número de especialistas en la generación de conocimiento tecnológico es notablemente inferior al número de usuarios potenciales

7 Trejo (1997: 41) ilustra este extremo de la siguiente manera: aAgilidad y velocidad: la comunicación cibernética depende de ellas y a su vez las promueve. A menudo, los datos se transmiten en cantidades tan abrumadoras que apabullan la posibilidad de evaluarlos. La velocidad es, por definición, inequitativa en estos asuntos. Más información y más rápido son casi seguros antecedentes de cibernautas más aturdidos. Pero no de un mundo mejor". 
hacia los cuales se dirigen los frutos de ese conocimiento. Son muchos los individuos que han oído hablar (aunque nunca se hayan conectado) de Internet. Pocos de ellos sin embargo saben que Internet se inició como respuesta a la necesidad militar de intercambiar información de manera inmediata. Tampoco conocemos la mayoría de los usuarios cómo se procesa la información interna que permite funcionar un ordenador, o por qué al presionar el botón derecho del mouse (ratón) se nos abre el acceso a una gran cantidad de funciones aplicables al documento en el que trabajamos.

Esta dicotomía entre profanos y especialistas se ha traducido en ocasiones en términos de consolidación de una élite. El conocimento circula y se transmite entre unos pocos, los cuales van ahondando la distancia que les separa de los meros usuarios. Pero una segunda dicotomía puede accionarse automáticamente: la que divide a aquellos (especialistas o no) capaces de operar un ordenador, de quienes no son capaces siquiera de trabajar con él. Tal vez este discurso nos lleve a la construcción cultural de dos nuevos macro-grupos sociales: los letrados - neoletrados- y los nuevos analfabetos. La última alfabetización de la sociedad se configura en torno a un nuevo idioma, una especie de llave maestra que abre nuevos espacios de circulación de conocimiento. Un idioma donde términos como "Software", "Internet", "hipertexto", "Sistema operativo", "módem", entre otros, suponen el repertorio de acceso necesario a estos nuevos canales de comunicación. No debe perderse de vista que las sociedades humanas se reproducen en el tiempo en buena parte gracias a la eficacia en la transmisión intergeneracional de información.

También se ha hablado de élite no en referencia a grupos de individuos dentro de un mismo sistema social sino incluso entre sistemas diferentes. En esta línea, Raúl Trejo (1997) cita al teórico norteamericano Steward Brand, quien ha llevado a cabo desde finales de los años ochenta una intensa labor de divulgación de las nuevas tecnologías, especialmente en lo referente a los cambios que se han producido en décadas recientes. Brand hace especial hincapié en el Laboratorio de Medios del Instituto Tecnológico de Massachusetts, conocido como Media Lab y, examinando la tarea que lleva a cabo, reflexiona:

Para como se están poniendo las cosas, las naciones del Tercer Mundo están destinadas a obtener comunicaciones primarias por satélite, en tanto que las naciones opulentas estarán conectadas por fibra óptica. Las audiencias de los satélites serán receptoras más pasivas de señales más tenues, porque los satélites son casi enteramente para transmisión en un solo sentido: hacia abajo. Las audiencias de la fibra óptica podrían ser más interactivas, en términos del Media Lab, con señales mucho más ricas. El pasivo se volverá más pasivo, el activo más activo, 
en un vistazo general de cada uno. Eso podría ser motivo de violencia. Las tecnologías de las nuevas comunicaciones son dinamita política (en Trejo 1997: 37).

Es obvio que con ello Brand eleva el debate a un nivel en el cual se combina el hecho de la desigualdad con su sistemática perpetuación. De forma similar a como Kathleen Kuehnast (1992) califica de imperialismo visual ciertas elaboraciones propias de la clase dirigente (y no únicamente en una dimensión bipolar occidente/no occidente, sino incluso dentro de todo sistema cultural que encierre grupos dominantes con posibilidad de perpetuarse en el poder y grupos subordinados, cuyas capacidades para plantear contra-modelos se vean segadas de raíz por acción las élites dominantes), Brand - y Trejo, con él- plantea el dominio de la tecnología como un factor más de desequilibrio en la dicotomía Primer Mundo/ Tercer Mundo y, esto es significativo, como una herramienta al servicio del mantenimiento estatutario de tal desequilibrio. De paso, se nos muestra cómo la noción misma de "nueva tecnología" tiene, por así decirlo, fecha de caducidad. La comunicación por satélite, buque insignia del desarrollo tecnológico hace unos años, queda en el futuro inmediato dibujada por Brand como completamente obsoleta. La "novedad" caduca irremisiblemente ante la última ola, de la que se esperan modificaciones (adelantosn) substanciales respecto a su predecesora.

Otra dimensión asociada al "impacto" social de las NTIC, es la aparente redefinición del término cultura o, cuanto menos, la aparición de un nuevo dominio de la cultura existente: la cibercultura. Superando el nivel estrictamente asimilatorio entre avance tecnológico y enriquecimiento cultural (lo que se ha denominado tecnocultura), aparece ante nosotros el que parece fértil terreno de la cibercultura o la cultura del ciberespacio. Estos híbridos terminológicos combinan acepciones más o menos familiares (cultura o espacio) con la actividad científica que surge a partir de la combinación de matemática, lógica y física, entre otras disciplinas, orientada al estudio del control y la comunicación. La antropología social y cultural comienza a aproximarse no sólo al ámbito particular de los "subgrupos" $O$ "subculturas" que integran el universo virtual, sino también a una etnografía de grupos vinculados por la cibernética, de forma similar a lo que Román Gubern llamó Antropotrónica y que venía a ser una “[...] ciencia transdisciplinar focalizada sobre el homo electronicus (prácticamente sinónimo de bomo informaticus y de bomo otiosus ${ }^{8}$ ) constituida

8 Gubern basa parte del uso de las nuevas tecnologías en el espacio reservado al ocio por los propios seres humanos. Distingue, para este propósito entre el ocio agorafílico (que no es otro que el que se disfruta en espacios públicos - lo que conlleva la distinción necesaria, y en su opinión radical, entre público y privado- 
como una antropología del ciudadano de la era electrónica cuya nueva identidad sociocultural y conducta trata de investigar y comprender" (en Rispa 1985: 30). Desde este punto de vista, la cibercultura comprendería aquel segmento de la cultura (cualquiera que sea) que se encarna y transmite a través del ciberespacio.

El término ciberespacio apareció por primera vez en un libro de William Gibson, Neuromancer, publicado en 1984 (Jones 1995). Desde entonces se ha aplicado cada vez con mayor profusión (especialmente desde la primera mitad de la década de los noventa) para hacer referencia a un "nuevo" tipo de espacio que se genera a partir de un determinado consumo informático: la comunicación mediada por computadores (CMC). Este fenómeno, en plena eclosión, comporta la conceptualización de un nueva dimensión espacio-temporal que llamamos virtual, esto es, existente en tanto concepto pero carente de entidad física. Así, Jones defiende la ilusoriedad del espacio y la problemática del tiempo en esta dimensión. Al igual que en los debates teóricos en antropología visual, referentes a productos audiovisuales como el llamado filme etnográfico o la fotografía aplicada a la investigación social, principalmente -aunque no de forma exclusiva-, el término "realidad" vuelve a estar de nuevo en el eje mismo de la polémica. En otro intento de definición, Colombain afirma: "La réalité virtuelle est une représentation réaliste d'un univers existant ou imaginaire. Ses applications sont nombreuses: ludiques, industrielles ou médicales" (1997: 23).

El uso que de estas nuevas tecnologías, y de la realidad virtual que se deriva, se ha efectuado, queda reflejado en numerosas producciones cinematográficas. Por ejemplo, filmes como Jurassic Park, en el cual se nos presentan estas NTIC en dos planos simétricos: a) por un lado, un empleo medicalizado de las mismas, en lo que podríamos considerar una representación cinematográfica del saber tecnocientífico: incubación de huevos de dinosaurio gracias a la extracción de muestras de ADN obtenidas a partir de mosquitos atrapados en ámbar cristalizado y b) la reflexión consecuente, que de nuevo vuelve a situarnos sobre la neutralidad inherente a la tecnología y la perversidad o bondad de los usos que de ella se hacen. Por otro lado, el filme mismo sitúa en su plano de realidad en pantalla la coexistencia de seres humanos con velocirraptores y tirano-

por ejemplo el teatro, el cine...) y el ocio claustrofóbico (en torno a los aparatos electrónicos que contribuyen a la bunkerización del hogar: ordenadores, videoconsolas, etc.). No obstante, admite también el uso "profesional" de las nuevas tecnologías (en este caso fundamentalmente relacionadas con la electrónica) que suponen funciones y gratificaciones diferentes pero complementarias. En esta línea estarían la telecompra, las videoconferencias o el teletrabajo. 
saurios... jvivos!. Evidentemente el espectador sabe que lo que aparece ante sus ojos no es real, aunque lo esté viendo. Es un efecto, un truco elaborado con ordenadores que permiten recrear e inventar la realidad. El espectador es consciente de ello porque ve esa película (ficción) en un cine (espacio teóricamente destinado al ocio a través de la ficción) y sabe que los dinosaurios se extinguieron hace más de sesenta millones de años. Pero, ¿qué ocurre en Forrest Gum? En este caso la coexistencia temporal es mucho más sutil. Forrest, el protagonista que encarna Tom Hanks, aparece en pantalla dando la mano al presidente de los Estados Unidos...jJohn F. Kennedy! La exclamación tiene, de nuevo, su porqué. Si prestamos atención a los créditos del filme, veremos que está realizado casi treinta años después de la muerte de Kennedy. ¿Cómo se consigue ese efecto tan verosímil? En primer lugar, manipulando la imagen, haciéndola aparecer en un formato diferente al del resto de la película. Identificamos este formato como característico de los informativos o documentales y, tal vez inconscientemente, tendemos a autentificar el contenido en virtud del continente. En segundo lugar, el personaje está estéticamente mimetizado en la cronología presentada: su corte de pelo, su forma de vestir o el entorno en que se mueve, nos remiten automáticamente más de dos décadas atrás. En tercer lugar, se están dando la mano... hay un contacto físico entre ambos personajes, ¿cabe mayor "prueba" de autenticidad? Cuando se nos explica el procedimiento técnico a través del cual la superposición de imágenes es posible, empezamos a identificar la ilusión. Pero, entonces ¿qué mecanismo convertiría la ilusión en fraude, o acaso se entenderían como la misma cosa? Inmediatamente podemos preguntarnos acerca de qué porcentaje de todo lo que vemos por televisión es efectivamente real y qué porcentaje es virtual. La diferencia puede pasarnos inadvertida. Vemos en un anuncio comercial transfigurarse la cara de un monstruoso animal en la de un joven afable y sonriente. Es de suponer que detectamos el montaje, y entendemos que esa transfiguración no es real. Se alude, de alguna manera, al contingente de empeiria acumulado que nos permite reconocer la verdad cuando la estamos viendo. De la misma manera que asociamos una determinada familia que aparece en una teleserie al modelo de familia tipo americana de clase media, por ejemplo. La cuestión esencial, a mi entender, es qué tipo de conocimiento nos permite establecer estas distinciones o estas asociaciones. De dónde proviene la verosimilitud genérica (Kilborn \& Izod, 1997) que nos facilita esas conexiones 9

9 Un ejercicio estimulante, que no se puede llevar a cabo aquí con mayor profundidad, es el de analizar las imágenes que se generan sobre nuevas tecnologías a través de las nuevas tecnologías. Es el caso de filmes como Juegos de Guerra, 2001. 
Capítulo aparte merece una producción de ciencia-ficción estadounidense que se estrenó con cierto éxito a comienzos de los noventa: Total Recall, traducida al castellano como "Desafío Total. En este filme, se presenta una agencia de servicios especializada en "fabricar" los recuerdos que cada uno elija para grabarlos después en su mente, creando así una ilusión absolutamente real. A partir de una visita a dicha agencia, el protagonista comienza a sospechar que fue sometido a un implante de memoria que no recuerda. Llega a dudar de su propia identidad y de todos aquellos que le rodean. No sabe si su vida ha sido o no una farsa. Realidad e ilusión se han mezclado hasta confundirse por completo. Más allá de sus loados efectos especiales y de la acción derrochada a lo largo y ancho del filme, se nos presenta una inquietante reflexión acerca de la posibilidad de "crear realidad", obligando a replantear conceptos como "ilusión" y "verdad". Sumidos en la duda sus recuerdos más íntimos, el personaje deambula sobre la cuerda floja de la virtualidad (la realidad inexistente, pero visible). No sabe que creer, ni a qué aferrarse, "parecía tan real...".

Volviendo momentáneamente al terreno estrictamente informático, la discusión es mucho más substancial de lo que en un primer momento puede parecer. Se trata, en el fondo, de elucidar si podemos seguir hablando de comunidades ("cibernautas", "internautas", etc.) desconectadas de espacios físicos (el ciberespacio no es ningún territorio, a menos que lo entendamos como territorio "Virtual"). Si los mecanismos de identidad siguen funcionando a través de los referentes considerados tradicionales (lengua, territorio, tradiciones y sistemas comunes de creencias, una estética compartida, una escala de valores consensuada, etc.) o debería darse cabida a nuevas variables identititarias ${ }^{10}$ : pertenece a la comunidad quien está conectado a la red. Jones (1995) entiende que la interpretación va por esta vía. Es decir, propone redefinir el término "comunidad" en torno al concepto de red social, en la medida en que las nuevas comunidades se crearían a través de las interacciones en la red de usuarios, entendida como red social ${ }^{11}$. De este modo, la varible temporal (histórica) pierde

Una odisea del espacio, Capricornio Uno... CD-ROM como Dirige tu película (donde Steven Spielberg "en persona" te invita a rodar tu propia película con el asesoramiento de guionistas, especialistas en efectos especiales... "de carne y hueso"), etc.

10 Por ejemplo, Rheingold afirma: "En forma similar a como los medios previos disolvieron las fronteras sociales relacionadas con el tiempo y el espacio, el más reciente medio de comunicaciones mediadas por ordenador $[\mathrm{CMC}]$ parecen también disolver las fronteras de la identidad (1996: 193).

11 Samuel Ebersole (1995: 1) cita a John Markoff refiriéndose a su firme convencimiento en el futuro productivo de la Red (en mayúsculas): “(...) the Web is poised to become the next mass medium. 
relevancia por cuanto una "comunidad" puede establecerse en un momento dado y funcionar únicamente en tanto haya interconexión entre los individuos (el caso, por ejemplo, de los foros virtuales). Las relaciones sociales pasan a estructurarse en este ámbito a través de la tecnología (la idea de interacción llevada a su, al menos por ahora, máxima expresión).

Sin embargo, Jones advierte sobre la gradación consciente de niveles de realidad. En tanto entidad existente fuera de la mera subjetividad de los individuos (y dejando al margen toda la discusión metodológica al respecto), la realidad se jerarquiza y se percibe estamentada. Para entendernos, si referirse a las comunidades virtuales es inevitablemente hablar de comunicación, un chat virtual jamás tendrá el mismo estatus de entidad objetiva (realidad) que la comunicación interpersonal cara a cara. Tampoco se trata de un sucedáneo; simplemente es otra opción, con sus ventajas y sus carencias, al igual que cualquier otra forma de intercomunicación humana. Curiosamente, lo que no exime esta nueva forma de percibir la comunicación es la dualidad ontológica que hay en su base. Sigue necesitándose un emisor y un receptor. Por más que en el caso de los foros o grupos de discusión virtual el receptor pueda adoptar la fórmula epistolar de "a quién corresponda (o esté interesado)".

El acto comunicativo, en esta dimensión, también precisa de un mensaje, de un código, un canal y un contexto. Según esto tampoco es tan diferente a la transmisión de información a través de un manual o de un informativo televisado, incluso a la comunicación cara a cara. Evidentemente, varían los elementos constituyentes (el receptor puede ser una comunidad de individuos únicamente limitada por el criterio de estar conectado/suscrito o no al grupo de discusión, el canal a través del cual circula el mensaje no adopta un formato "Convencional" - papel, cinta magnética, la voz, las ondas hertzianas, etc.-), pero el proceso en sí, sigue estructurándose sobre los mismos estadios ${ }^{12}$.

¿Es posible, entonces, hablar de una sociedad virtual? ¿Es factible construir nuevas identidades? ¿Estamos asistiendo a una nueva conceptualización de la realidad? Los interrogantes que se abren son numerosos y tal vez sea prematuro aventurar respuestas, entre otras cosas porque toda respuesta es, en cierta medida, excluyente y no es propósito de este ensayo cerrar puerta alguna, sino más bien ayudar a formularnos ciertas cuestiones. Abonar, por así decirlo, el terreno del debate.

12 Rheingold llega a afirmar, tal vez de forma un tanto exagerada, que "Es evidente que muchos de nosotros nos comunicamos con muchas más personas cada día, vía teléfono, fax y correo electrónico, que lo que nuestros abuelos se comunicaban en un mes, un año o toda una vida" (1996: 219). 
Siguiendo a Thomas Leary (Jones 1995) casi sería desmesurado escandalizarse ante esta nueva concepción del espacio nocional, de la realidad inexistente (esto es, virtual) si tenemos en cuenta que desde la misma invención de la televisión hemos convivido con ella. Nos hemos habituado a ver la encarnación de lo inexistente. La utilización de chromas en el plató nos permite "ver" al meteorólogo abarcando con su mano el contorno de una masa nubosa o a un personaje sentado sobre un avión en pleno vuelo. Los niños y niñas, que desde su nacimiento han visto un televisor en su hogar, no se sorprenden ante sus imágenes, la cuestión es si las entienden como reales; o si tan sólo se lo plantean. Por otro lado, ¿no autentifica la audiencia los contenidos de ciertos productos audiovisuales emitidos por televisión bajo el formato de programas informativos? ¿No podría hacerse creer a la audiencia que el ser humano ha llegado a Marte, realizando un simulacro en un plató de televisión (argumento de la película de ficción Capricornio Uno, por ejemplo)? ¿Disponemos de capacidad crítica suficiente como para discernir todos estos niveles de información en los productos de las nuevas tecnologías, cuando seguimos discutiendo si somos capaces de hacerlo ante los medios audiovisuales "Convencionales"?

\section{ADEMÁS DE LA INFORMÁTICA...}

Parece haber una coincidencia implícita en muchos de los teóricos que se aproximan al mundo de las nuevas teconologías y su repercusión en las formas de organización social desde perspectivas, digamos, no estrictamente tecnológicas, en convertir al ordenador en el eje instrumental de esta "revolución". Sin embargo, las NTIC no son exclusivamente informáticas, aunque es cierto que en muchos casos la informática está directamente relacionada (sistemas de edición no lineal de imagen y sonido, tarjetas gráficas, etc.). En algunas ocasiones, la informática es parte del transfondo de un decorado que se nos aparece con otro aspecto. Es el caso de la televisión digital.

En un estudio disponible en su versión on-line ${ }^{13}$ desde el 12 de mayo de 1997 (y redactado para publicarse en Global Communications), Luis Castejón, Claudio Feijóo, Raquel de Juanes y Jorge Pérez analizan los

13 Para consultas on line, la dirección electrónica de este artículo publicado por el Grupo de Tecnologías de la Información y las Comunicaciones, Departamento de Señales, Sistemas y Radiocomunicaciones, de la Universidad Politécnica de Madrid, es: hhtp://www.gtic.ssr.upm/artihtm/artregul.htm. 
conflictos establecidos entre las distintas plataformas de televisión digital en función de "las actividades fundamentales que componen la cadena de valor del sector de los servicios de la TV digital" (p. 2). Así, constatan que en los EE.UU. existen un total de 97 millones de hogares equipados con un receptor de televisión (casi el 100\% del total), de los cuales el 74\% (71.780.000 hogares) están abonados a alguna forma de televisión multicanal. En 1997 operaban cuatro plataformas digitales (PrimeStar, Dish, AlphaStar, DirectTV), con una cuota de mercado del 4,92\% en octubre de 1996 y un crecimiento anual del $110,45 \%$ respecto al año anterior, según datos extraídos de la misma fuente. En Europa (15 países) el porcentaje de hogares en los cuales se encuentra por lo menos un receptor de televisión es apenas del $89 \%$. Pasemos a observar a continuación el panorama español a partir de los datos que ofrecen estos autores.

En España (sin contar televisiones públicas autonómicas) hasta 1990 existía un régimen de monopolio estatal de RTVE que, bajo TVE, emitía TVE1 y TVE2. Desde entonces hasta 1997, el panorama se ha diversificado notablemente: TVE sigue emitiendo dos canales TVE1 y TV2, pero se le han añadido dos grandes cadenas privadas competidoras a nivel estatal en régimen abierto (Antena3 y Telecinco) y una en régimen parcialmente codificado (Canal+). En lo que se refiere a la oferta pública el mapa añadido queda como sigue: TVE de Canarias, TV3 y Canal 33 - Cataluña-, ETB1 y ETB2 - País Vasco-, TVG - Galicia-, Canal Sur - Andalucía-, Canal 9 -Comunidad Valenciana- y Telemadrid - Comunidad Autónoma de Madrid). Esto por lo que se refiere únicamente a la televisión terrenal. Según datos obtenidos por el Grupo de Tecnologías de la Información y las Comunicaciones, recogidos por los autores en esta misma publicación, el número estimado de hogares españoles que sobre el año 2007 contarán con televisión digital por satélite estaría rondando los tres millones. La inversión acumulada necesaria sería de unos 120.000 millones de pesetas y los beneficios acumulados se calculan en torno a 300.000 millones. Estas cantidades nos dan una idea acerca de la dimensión (económica y social) que adquiere la incorporación de las NTIC por lo que a la televisión digital se refiere.

De nuevo, estas magnitudes pueden distraer nuestra atención. Hoy, cualquier hogar situado en un área orográficamente adecuada del territorio estatal, con cobertura de señal suficiente, puede recibir hasta seis o más canales de televisión terrenal (sin contar emisiones de TV por satélite, en cuyo caso el número se multiplicaría por varias decenas). Además, cada vez es más frecuente el servicio interactivo que permite enlazar ordenadores y receptores de televisión. Con ello se diversifica la gama de opciones y la oferta de cadenas y canales, aunque no se modifiquen también cualitativamente. 
La aportación de las televisiones autonómicas se ha percibido como relevante, desde un punto de vista genéricamente "cultural", por parte de las autoridades gubernativas en cada comunidad autónoma en concreto. De un lado, el mayor énfasis - $a$ priori- efectuable sobre referentes identitarios de primer orden (lengua, tradiciones, simbología, etc.) y, de otro, la posibilidad de transmitir esos referentes por, para y a través de los propios sujetos socialmente identificados como comunidad, parece constituir un argumento más en el debate entre universalismo y diferencialidad. La Europa de las naciones, encarnada en la Europa de las televisiones traduce este debate en una auténtica arena mediática. Los conflictos subyacentes ( $\mathrm{y}$ no siempre intencionalmente verbalizados) entre cadenas de televisión asociadas a tendencias político-sociales y culturales "particularistas", y las cadenas de televisión "estatalistas" ponen de relieve aquello que, llevado al extremo, algunos antropólogos han denominado "fundamentalismo cultural.

Entender la televisión como un medio de comunicación (y, por ello, esencialmente como un medio de transmisión de información) de masas obliga a prestar especial atención a su repercusión en la sociedad/audiencia que la recibe. Los canales temáticos pudieran a primera vista parecer libres de este sesgo "fundamentalista". Sin embargo, no debemos perder de vista que selección y decisión son conceptos indisociables. Las mismas imágenes de un partido de fútbol son narradas con un pathos diferente en comunidades autónomas diferentes. La selección de documentos audiovisuales puede también obedecer a intereses distintos. Los criterios de selección pueden depender de variables como audiencia, intereses corporativos, actualidad del fenómeno filmado, repercusiones que se calculen tras su emisión, etc.

Obviamente, por su carácter, éste ensayo no es el marco adecuado para profundizar en este ámbito. Quede, no obstante, constancia de que los fenómenos mediáticos de masas no lo son fortuitamente, ni fruto de azares caprichosos. Los temidos índices de audiencia se realizan sobre el cómputo de la opción común y simultánea de millones de espectadores. La imagen que la "gente de la calle" tiene de un indio, ¿le ha venido principalmente a través de las películas que ha visto en el cine y en la televisión, o acaso su fuente de conocimiento debe buscarse en las monografías etnográficas? La cuestión no es nimia en absoluto.

\section{PERSPECTIVAS Y PLANTEAMIENTOS}

Parece arriesgado aventurar las líneas de investigación futuras que desde las ciencias sociales pueden llevarse a cabo sobre las NTIC. Entre otras 
cosas porque nos encontramos en plena eclosión del fenómeno en España y todavía existen pocos ensayos sistemáticos y en profundidad realizados desde la antropología o la sociología, por citar dos disciplinas de las llamadas ciencias blandas (aunque su inclusión en este grupo no está exenta de polémica). Es cierto que los antropólogos estamos todavía descubriendo Internet. Un ilustre analista de la historia de la antropología, George Stocking, comentaba en un reciente encuentro en la Universidad de Barcelona la aparente ubicuidad del acercamiento académico al trabajo de campo. "Si estás interesado en un grupo del norte de China, hay webs, chats, etc. a través de los cuales tienes acceso inmediato a gran cantidad de información al respecto", comentaba entre sorprendido y admirado. Pero no solamente podemos extraer información, también podemos abrirnos nuevos interrogantes. El ciberespacio parece comportar la globalización de la comunicación, combinando los efectos de inmediatez (el correo electrónico te permite comunicar con cualquier otro usuario prácticamente al instante -tiempo-) y ubicuidad (puedes entrar a cualquier web desde cualquier sitio del mundo que disponga de la posibilidad de conectarse - espacio-). Pero al mismo tiempo se abre camino en contextos que reclaman atención sobre hechos diferenciales, especificidades culturales, construcción de identidades por oposición, etc. Esta cultura virtual de la que habla Jones o la comunidad virtual de Rheingold deben resolver en su construcción la tensión existente entre la globalización y el particularismo.

No es infrecuente encontrar en la literatura expresiones que aludan directamente a esta tendencia universalista. Así, se habla de la comunidad global o la aldea global (Trejo 1997), para referirse a la generalización de los mecanismos de transmisión de la información. Curiosamente, esta globalización se muestra parcial en cuanto se toman en cuenta aspectos como la perpetuación del status quo internacional. Llegados a este punto, puede pensarse en la paradoja aparente de una universalización parcial o, si se prefiere, una universalización que mantiene las diferencias estatutarias, ahondadas y arrastradas a lo largo del siglo xx. La aldea global comprendería, por así decirlo, barrios diferentes, en los cuales los marcadores de status se traducirían en la cantidad y calidad de los sistemas de acceso a la información, la factibilidad de generarla o la dependencia de países tecnológicamente exportadores (cuya influencia es percibida muchas veces en términos de colonización cultural y tecnológica).

Por otro lado, la propia noción de "modernidad" está cambiando, al menos en lo referente a su acepción popular. Hoy en día queda descolgado de la modernidad el sujeto que no es capaz de abrir un procesador de textos, que se considera incapaz de programar un vídeo o que sigue 
comprando exclusivamente discos de vinilo. Tecnicismos y neologismos como "Web", "Chat" "e-mail", "servidor", etc. comienzan a formar parte del lenguaje cotidiano de un sector cada vez más amplio de población (los usuarios). Trejo se mantiene en la opinión de considerar estos neologismos como propiedad de una minoría. Tal vez sea así, pero no debemos obviar el hecho de que dicha minoría es cada vez más numerosa.

Algunas corrientes teóricas de la antropología visual (o, como yo prefiero llamarla, antropología 'audiovisual, puesto que el sonido constituye un elemento substancial en cualquier producción que combine audio e imágenes) han apuntado, desde mediados de los años 80 , un desplazamiento del foco de interés analítico. De las representaciones en sí mismas, se ha pasado a examinar las estrategias representacionales que acaban configurando el producto final que contemplamos. De alguna manera, pudiera decirse que el objetivo no es tanto aprender sobre el "otro" representado, como profundizar en "nuestro" autoconocimiento a través del proceso de construcción de la alteridad. La pantalla que durante décadas se entendió como una ventana a través de la cual contemplábamos al "otro", deviene ahora un espejo que nos devuelve nuestra propia imagen. Los trazos imprecisos del "nosotros" que acechan tras la cámara, confortablemente agazapados en la relación asimétrica que cree tener aquél que "va" a estudiar y no se percibe a su vez estudiado.

Otras líneas teóricas recientes en esta disciplina se han detenido a reconsiderar la posición de autoridad del etnógrafo/cineasta. La crisis de la representación, que puso de relieve el proceso de autoconciencia por parte del etnógrafo, llegó a contar con partidarios de "dar la cámara" a los propios indígenas, los tradicionalmente representados. El Indigenous filmmaking o la autoetnografía fueron intentos decididos de dar voz y presencia a aquellos que eran simplemente informantes. Se les traspasaba la cámara, se les adiestraba en ciertos procedimientos técnicos que les permitiesen operarla y se analizaban los resultados (Worth y Adair con los Navajo a comienzos de los 60). En otros casos, se incorporaban los comentarios de los protagonistas que, de esta manera, sustituían a la ubícua voz del antropólogo (como hizo Rouch en Jaguar, por ejemplo). Para muchos, entre los que se cuenta Minh-Ha (1993), estos intentos no eran otra cosa que proyecciones etnocéntricas sobre los "otros". La etnoverdad comenzaba a buscarse no ya en la propia filmación e interpretación dirigistas por parte del "nosotros", sino en el reflejo de nuestra huella en la obra de los otros. En otras palabras, dejarles la cámara a ellos, situándolos en las convenciones fílmicas occidentales, no haría otra cosa que perpetuar ese imperialismo visual del que hablaba Kuehnast (1992). 
¿Es aplicable este análisis al ciberespacio? Los reclamos por parte de los países no punteros en la generación y exportación de tecnología respecto al colonialismo, principalmente estadounidense, que invade la difusión de las nuevas tecnologías parecen remitirnos de alguna manera a este tipo de análisis. En sistemas socio-culturales con vocación filotecnológica, donde el progreso se conceptualiza y se mide más por la tecnometría ${ }^{14}$ que por la tecnología, parece plausible apuntar, en la línea de la teknosis de Biram, que la obsesión por la tecnología, su conceptualización como panacea para el progreso social, llegue asociada a un consumo supuestamente indiferenciado y acrítico de referentes culturales asociados a la sociedad exportadora. El temor a la colonización tecnológico-cultural indiscriminada hace reaccionar a ciertos sectores sociales (estaría por ver si éstos coinciden exactamente con los segmentos que presentan un rechazo más patente hacia la penetración tecnológica), clamando por una mayor autoconciencia por parte de los usuarios de la red. Tal vez también aflore el temor a diluir la identidad propia en la virtualidad del ciberespacio. La novedad y la explosión actual de un fenómeno con un crecimiento espectacular en los escasos años de su existencia (y cuyas expectativas de expansión crecen cada día) exigen prudencia ante este tipo de planteamientos. El temor a que la imagen y el sonido destierren a la palabra escrita no es nuevo, pero parece cobrar vigor con la irrupción de las nuevas tecnologías electrónicas e informáticas. Suele decirse que es difícil definir (poner límites) desde el interior del propio elemento del cual se quiere dar cuenta. Tanto más difícil cuanto menor sea la distancia, física o temporal, entre el observador y el objeto de la definición. Desde esta perpectiva, estamos aún en los albores de un fenómeno cuya potencial explotación se nos aparece ciertamente descomunal.

En cierto modo, algunos planteamientos sobre el ciberespacio se asemejan a un espectacular número de magia. El mago procura cautivar al espectador sumiéndole en un universo de ilusión. Lo que éste contempla, como en el escenario de un teatro, es siempre la fachada del espectáculo, aquella parte meticulosamente calculada para ser observada, escrutada. La atmósfera en que se sumerge el actor/mago debe parecer la realidad, de manera que el público crea que consiguió hacer desaparecer a su ayudante de la jaula, o atravesó el cuerpo de un voluntario con un gran número de espadas. No importa que la jaula esté cubierta con un velo o que de la víctima del acero solo veamos la cara y quizá una mano agi-

\footnotetext{
14 Propongo este término para denominar la cuantificación del uso de tecnología a partir de indicadores directamente mesurables, en lugar de analizar las causas y consecuencias de su implantación en una sociedad determinada.
} 
tando un pañuelo. Sabemos lo que ocurre. Lo inferimos de las palabras dramáticamente pronunciadas por el conductor del show, de la atmósfera que nos envuelve y de todos y cada uno de los números que hemos contemplado ya en el pasado y se convierten ahora en bagaje de conocimiento. La actuación no ha acabado, pero sabemos que la jaula estará vacía.

La realidad en la que se ha creído vivir durante unos minutos o unas horas, se relativiza después. Si la ejecución del truco ha sido satisfactoria, posiblemente hayamos experimentando de alguna manera la realidad virtual. Sabemos que un ser humano no puede volar sin la ayuda de la tecnología, sin embargo nos admiramos ante el mago que cruza el escenario surcando el aire. No nos levantamos y gritamos indignados que lo que se nos presenta es un fraude. No lo es, porque no lo percibimos como absolutamente real. Jugamos constantemente con los límites entre la realidad y la ficción/ilusión. ¿Qué otra cosa es la realidad virtual más que un paseo a lo largo de esa frontera?

En términos más académicos, puede empezar a pensarse en una antropología del ciberespacio compuesta por cibernautas-antropólogos que se aproximan al estudio de la tecnología ( $y$, a través de ella, de los grupos humanos que se estructuran a su derredor) desde la propia tecnología. No se anula con ello el tan característico trabajo de campo, sino que únicamente puede adquirir una dimensión diferente. El etnógrafo es también usuario, forma parte de la comunidad virtual a la que algunos aluden. Es, en toda la extensión de la palabra, un sujeto participante.

En la vida cotidiana, las NTIC también comienzan a tener su impacto. La aparición de instrumentos cuyo uso se va convirtiendo en un hábito asimilado por los seres humanos, por ejemplo los niños que ya han crecido con un aparato de televisión en casa, un teléfono, ahora un ordenador doméstico, etc. no perciben estos aparatos como "novedad", el aprendizaje en medio y a través de ellos no les es problemático en absoluto. A los adultos, en cambio, les obliga a repensar el espacio doméstico. Así, quienes diseñan las vivendas deben tener presente la instalación de antenas, conductos para albergar los cables de fibra óptica, etc. Paralelamente, los inquilinos deben organizar su espacio acomodando el receptor de televisión, el equipo de alta fidelidad, el teléfono y el ordenador. Los productos de la tecnología (los instrumentos) ganan espacio físico en nuestras vidas al mismo tiempo que estandarizamos su uso, es decir, lo convertimos en habitual.

Por último, también el ámbito del trabajo y la educación está siendo sacudido por las NTIC. Hoy en día existen universidades que facilitan el seguimiento académico a través de la conexión electrónica. Ésta es una de 
las máximas de la UOC (Universidad Abierta de Cataluña) o el "Campus Virtual", por ejemplo, el de la Universidad Autónoma de Barcelona, a través del cual los alumnos pueden tener acceso a los programas de las asignaturas, la bibliografía, incluso a comentarios interactivos con el personal docente, a través de la pantalla de ordenador. Los sistemas educativos de autoformación comienzan también a generalizarse. Con ello se abre la posibilidad a la descentralización de las actividades, no siendo imprescindible desplazarse regularmente al aula a seguir las clases, sino que éstas se atienden en régimen interactivo. Desde el propio domicilio puede accederse a las web (esto es, páginas electrónicas personalizadas) más recónditas y navegar a través de sus múltiples interconexiones. Esa es la esencia misma de la bipertextualidad: viajar a través de un documento enlazando con otros vinculados a él (links). Muchas de estas páginas web tienen un contador que informa al navegante sobre el número de visitas, procedentes de todos los rincones del planeta que gozan de facilidades de conexión, que ha recibido desde una fecha determinada. La elaboración de listados de webs ordenados jerárquicamente en función del número de visitas que han recibido y el tratamiento análitico de esa información, puede serle de gran utilidad al investigador social. Las cifras pueden convertirse en indicadores de unas pautas de actuación o unos valores que pueden ser tratados a nivel global (de toda la cibercomunidad) o particular (los accesos de cibernautas ajustándose a los límites estatales, por ejemplo).

No cabe duda de que nos encontramos en la eclosión de un nuevo fenómeno que se intuye de masas. La desorbitada velocidad de su crecimiento y expansión arroja cifras mareantes, insospechadas en la diseminación de aplicaciones tecnológicas previas. La velocidad en el procesamiento y la transmisión de información es un denominador común de las NTIC, que parecen acercarse así a la vieja quimera de la instantaneidad. En este sentido, como señalan algunos autores, el tiempo en la red también es oro. Y no se trata de oro virtual. La conexión cuesta dinero; el tiempo que se está conectado también. El nuevo mercado mundial que se abre (teletrabajo, telecompra, suscripciones electrónicas, etc.) crece tanto en servicios disponibles —oferta — como, sobre todo, en el número de consumidores potenciales que se adivina - demanda- El negocio está en marcha. La transformación de nuestros hábitos culturales cotidianos, también.

\section{BIBLIOGRAFÍA}

BANKs, M. \& E. MORPHY (eds.), 1997: Rethinking Visual Anthropology, New Haven: Yale University Press. 
Barroso, Porfirio, 1997: "Cuatro principios de ética en Internet", Zer (noviembre). Edición electrónica: http://zerrev.lp.ehu.es/Zer/HTML/2.ART.BARR.html

Bernal, Francisco Javier, 1985: La extensión tecnológica del conocimiento, Madrid: Editorial de la Universidad Complutense.

BorN, Georgina, 1997: "Computer software as a medium: textuality, orality and sociality in an artificial intelligence research culture", en M. Banks \& E. Morphy (eds.), $o p$. cit., pp. 139-169.

CaStejón, Luis; Claudio Fejóo; Raquel De JuAnes [et. al.], "La regulación y el mercado de la TV digital por satélite. Documento para su publicación en Global communication, 12 de mayo de 1997. Consulta electrónica del texto en: http:// www.gtic.ssr.upm.es/artihtm/artregul.htm

Chander, Daniel, 1998: "What is technology?» (mayo). Publicación electrónica disponible en: Wysiwyg://144/http://www.aber.ac.uk/(ednwww/Undgrad/ED10510/ whattech.html

Colombain, Jérome, 1997: La Cyberculture, Toulouse: Les essentiels Milan.

CRAwFORD, P. I. \& D. TURTON (eds.), 1992: Film as ethnography, Manchester: Manchester University Press.

Ebersole, Samuel, 1995: “Media Determinism in Cyberspace». Edición electrónica: http:/ /www.regent.edu/acad/schcom/rojc/mdic/md.html

ECHEVARRía, Javier, 1994: Telépolis, Barcelona: Ediciones Destino.

GiBson, W., 1984: Neuromancer, New York: Ace Books.

HAKKEN, David, 1999: "Towards an Anthropology of Cyberspace". Manuscrito pendiente de publicación en Revista d'Etnologia de Catalunya, n. ${ }^{\circ}$ 14, abril de 1999.

JONES, Steven G., 1995: Cybersociety, London: Sage.

KILBORN, R. \& J. IZOD, 1997: An Introduction to Television Documentary, Manchester: Manchester University Press.

KUEHNAST, K., 1992: "Visual Imperialism and the export of prejudice: an exploration of ethnographic film", en P. I. Crawford \& D. Turton (eds.), op. cit., pp. 183-195.

MacDougall, David, 1997: "The Visual in Anthropology", en M. Banks \& E. Morphy (eds.), op. cit., pp. 276-295.

MCLuhan, M., 1964: Understanding Media, London: Routledge \& Kegan.

MinH-HA, Trinh T., 1993: "The totalizing quest for meaning", en M. Renov (ed.), op. cit., pp. 90-107.

ReESE, J.; H. KUBICEK; B. P. LANGe [et. al.], 1982: El impacto social de las modernas tecnologías de información, Madrid: Tecnos.

Renov, M. (ed.), 1993: Theorizing Documentary, New York: Routledge.

RHEINGOLD, Howard, 1996: La comunidad virtual, Barcelona: Gedisa [1994].

RIERA I TUÈBols, Santiago, 1994: Més enllà de la cultura tecnocientífica, Barcelona: Edicions 62.

RisPa, Raúl (ed.), Nuevas tecnologias en la vida cultural española, Madrid: Fundesco.

SANTANA, Beatriz, 1997: "Introducing the Technophobia / Technophilia Debate: Some Comments on the information Age" (junio), Education, Technology \& Society, UCLA Department of Education. Edición electrónica: http://www.gseis.ucla.edu/courses/ ed253a/beatriz,htm

Seaman, G. \& H. Williams, 1992: "Hypermedia in Ethnography", en P. I. Crawford \& D. Turton (eds.), op. cit., pp. 300-311.

Tezanos Tortajada, José Félix y Antonio López Peláez (eds.), 1997: Ciencia, tecnologia y sociedad, Madrid: Sistema. 
TRejo Delarbe, Raúl, 1996: La nueva alfombra mágica, Madrid: Fundesco.

Wolf, Mauro, 1997: "Los emisores de noticias en la investigación sobre comunicación",

Zer (noviembre). Edición electrónica: http://zerrev.lp.ehu.es/Zer/HTML/

1.ART.WOLF.html

Las llamadas Nuevas Tecnologías de la Información y la Comunicación (NTIC) están siendo objeto de un incipiente debate en el área de las Ciencias Sociales. La difusión y arraigo de estas nuevas tecnologías en la práctica social comportan la modificación de nuestros hábitos y costumbres en función de la implantación de nuevos instrumentos en nuestro quehacer cotidiano. Este artículo pretende una reflexión, alumbrada desde la perspectiva antropológica en general (y de la antropología audiovisual en particular), acerca del impacto que desde el punto de vista sociocultural están teniendo las NTIC. Con ello se pretende reconceptualizar nociones como "tecnociencia", "identidad", "realidad virtual" o "redes sociales", entre otras. La conclusión invita a examinar el fenómeno en su repercusión social más cotidiana, a saber: los usos que a diario hacemos de televisión por cable o Internet, el espacio (físico y conceptual) que ocupan en nuestras vidas y la ubicación en nuestra escala de valores del uso de instrumentos tecnológicos y del saber tecnocientífico que se les asocia.

The so-called New Technologies of Information and Communication (NTICs) are the subject of an incipient debate in the social sciences. The increasing presence of these technologies in everyday social practice is bringing about changes in our habits and customs. The author reflects upon this phenomenon with the analytical tools of anthropology, especially those of audiovisual anthropology. He seeks to reconceptualize notions such as "technoscience", "identity", "virtual reality", "Social networks" and others. His conclusions invite the reader to examine the phenomenon in its most commonplace effects: the everyday use of cable TV and the internet, the physical as well as conceptual space this usse occupies in our lives, and the placement of he new technological instruments - and the technoscientific knowledge associated with them- in our system of values. 

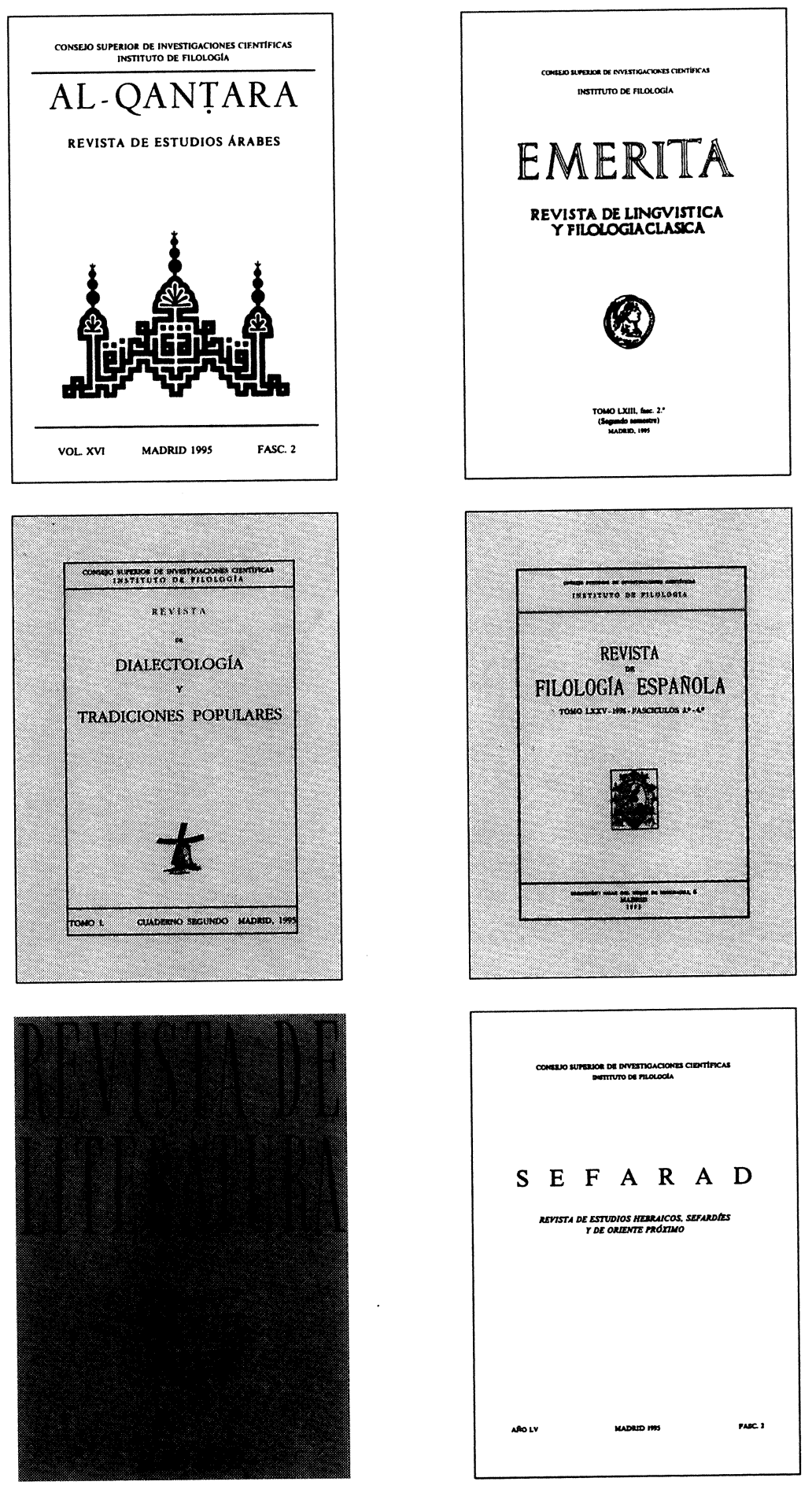